\title{
Sn-Cu/KNT Kompozit Kaplamaların Pulse Elektro-biriktirme ile Üretimine Akım Yoğunluğunun Etkisi
}

\author{
${ }^{* 1}$ Harun GÜL, ${ }^{2}$ Mehmet Uysal, \\ ${ }^{1}$ Gumusova Meslek Yüksek Okulu, Düzce Üniversitesi, Düzce \\ harungul@duzce.edu.tr \\ ${ }^{2}$ Sakarya Üniversitesi, Mühendislik Fakültesi, Metalurji ve Malzeme Mühendisliği Bölümü, Sakarya \\ mehmetu@sakarya.edu.tr
}

Geliş Tarihi: 2017-08-25 Kabul Tarihi: 2017-12-27

\begin{abstract}
Öz
Li iyon piller günümüzde artan bir ilgi ile taşınabilir elektronik cihazlar için yeniden şarj olabilir piller olarak ana güç kaynağı olmaya başlamışlardır. Ancak ticari pillerde anot malzemesi olarak kullanılan grafitin yeterli performans sergileyememesinden dolayı alternatif arayışları devam etmektedir. Bu nedenle alaşım matrisli kompozit anotların kullanımına yönelik çalışmalar yapılmaktadır. Bu çalışmada da $\mathrm{Sn}-\mathrm{Cu}$ matrisli KNT takviyeli kompozit anotlar pulse elektro biriktirme ile üretilmiş olup, akım yoğunluğunun etkisi incelenmiş̧tir. Sn-Cu/KNT kompozitleri pirofosfat banyosunda bakır altlık üzerine pulse elektrokompozit kaplama tekniği ile hazırlanmıştır. Üretilen kompozit malzemeler CR2016 buton pilinde anot olarak kullanılarak elektrokimyasal olarak test edildi. Anot malzemelerinin fiziksel ve elektrokimyasal özellikleri çeşitli analiz teknikleri kullanılarak araştırıldı. Sonuçlara göre, kesikli akım (PC) elektrokompozit kaplamada en iyi çevrim performansını $80 \mathrm{mAcm}-2$ akım yoğunluğu ile üretilen $\mathrm{Sn}-\mathrm{Cu} / \mathrm{KNT}$ kompozit anot göstermiştir.
\end{abstract}

Anahtar kelimeler: Lityum iyon pil, alaşım kompozit kaplama, pulse elektrolitik kaplama, akım yoğunluğu

\section{Effect of Current Density on Production of Sn-Cu/CNT Composite Coatings By Pulse Electrodeposition}

\author{
${ }^{* 1}$ Harun GÜL, ${ }^{2}$ Mehmet Uysal, \\ ${ }^{1}$ Gumusova Vocational High School, Duzce University, Duzce \\ harungul@duzce.edu.tr \\ ${ }^{2}$ Sakarya University, Faculty of Engineering, Department of Metallurgical and Materials Engineering, Sakarya \\ mehmetu@sakarya.edu.tr
}

\begin{abstract}
$\mathrm{Li}$ ion batteries have started to become the main power source as batteries that can be recharged for portable electronic devices with an increasing interest nowadays. However, since the graphite used as an anode material in commercial batteries cannot exhibit sufficient performance, alternate quests continue. For this reason, studies are being made for the use of alloyed matrix composite anodes. In this study, composite anode with $\mathrm{Sn}$-Cu matrix is fabricated by pulse electrodeposition and the effect of current density is investigated. Sn-Cu /CNT composites were prepared by electroplating on a copper substrate in a pyrophosphate bath. Composite materials produced were electrochemically tested as anode in CR2016 button cell. The physical and electrochemical properties of anodic materials were investigated using various analysis techniques. According to the results, the Sn-Cu /CNT composite anode showed the best cycle performance in the pulse current (PC) electrocomposite coating with a current density of $80 \mathrm{mAcm}-2$.
\end{abstract}

Keywords: Li-ion battery, alloy composite coating, pulse electrodeposition, current density. 


\section{GİRIş̧}

Lityum-iyon piller, günümüz taşınabilir elektronik cihazları için şarj edilebilir pillerin temel güç kaynağı olarak gözükmektedir. Günümüz ticari lityum iyon pillerinde anot malzemesi olarak grafit kullanılmaktadır. Ancak, karbon ilk döngü itibari ile çok hızlı bir şekilde bozulma göstermektedir. İlk döngülerdeki çok hızlı bozulmanın temel nedeni elektrolit ile elektrot yüzeyinde oluşan ve katı elektrolit arayüzeyi adı verilen bir pasivasyon tabakasıdır. Ancak yüksek performanslı materyallerin araştırılması hala aktif bir alandır. Örneğin, kalay, yüksek kapasite nedeniyle Li-ion piller için potansiyel anot malzemelerinden biridir. İlk döngülerdeki hızlı bozulmanın önüne geçilebilmesi amacıyla karbonun elektrokimyasal özellikleri, yapısal modifikasyonlar, tekstür kontrolü, yüzey modifikasyonları ve diğer elementlerle bileşik yapma gibi yöntemlerle geliştirilmeye çalışılmıştır. $\mathrm{Bu}$ nedenle, son yıllarda hem taşınabilir elektronik cihazlar hem de elektrikli araçlar için lityum-iyon pillerin en umut verici güç kaynağı olduğu düşünülmektedir [1-5].

Özellikle anotta meydana gelen yapısal bozulmanın önüne geçebilmek amacıyla yaygın olarak grafit anot yerine alaşım esaslı veya intermetalik anotlar ve kompozit anotlar çalışılmaya başlanmıştır. Çevrim sayısını arttırabilmek ve elektrokimyasal performans1 arttırabilmek için Sn-Co, $\mathrm{Sn}-\mathrm{Fe}, \mathrm{Sn}-\mathrm{Ni}, \mathrm{Sn}-\mathrm{Sb}$ ve $\mathrm{Sn}-\mathrm{Cu}$ benzeri $\mathrm{Sn}-\mathrm{M}$ alaşım anotlar kullanılmaya başlanmıştır. Alaşım veya intermetalik malzemelerin anot malzemesi olarak kullanılması ile;

Sn-M alaşımları oluşturularak ve intermetalik bileşikler dizayn edilerek inaktif fazlar oluşturulmakta ve bu fazlar ile büyük hacimsel değişime engel olabilecek matris malzemesi elde edilmektedir, Sn-M alaşım elektrotlar saf kalaya göre daha yüksek çevrim performansı sergilemekte, ayrıca akım toplayıcı bakır altlıklar kullanılarak kalay elektrotun elektrokimyasal performansi artırılmakta ve elektrokimyasal kararlılık kazandırmaktadırlar, Bir alaşım elektrotun performansı inaktif bileşiklerle arttırılabilmektedir. $\mathrm{Bu}$ da $\mathrm{Sn}-\mathrm{Cu}$ alaşımlarında
Cu6Sn5 fazının elde edilmesi ile sağlanmaktadır [6-15].

Kalayın yüksek teorik kapasitesinden dolayı kalay esaslı elektrotlar üzerine çalışmalar yoğun bir şekilde devam etmektedir. Kalay esaslı elektrotlarda kompozit yapma çabaları alaşım oluşturmadaki amaçlarla örtüşmektedir. Kompozit oluşturmada da alaşım yapmadaki hedeflerimize benzer şekilde kalayın yüksek olan hacimsel genleşmesinin önüne geçme çabası söz konusudur. İlave edilen ikincil fazlar yardımıyla söz konusu yüksek hacimsel genleşmeyi engelleyecek bir yapıya sahip olmak asıl hedeftir [16]. Elektrolitik olarak kompozit kaplama mikron veya nano boyutlardaki partiküllerin bir kaplama çözeltisine ilave edilip, bu partiküllerin katotta alaşım ya da metal matriks ile birlikte çöktürülmesi ile elde edilir [17-20].

$\mathrm{Bu}$ çalışmanın amacı grafitten çok daha üstün niteliklere sahip, bu tür pillerdeki mevcut katot sistemleri ile uyumlu olan ve mevcut elektronik cihazların daha etkili bir şekilde kullanılmasına yardımcı olabilecek alternatif kompozit esaslı bir anot malzemesi geliştirmektir. Bu nedenle yapılan çalışmasında aktif olmayan bir altlık (bakır) üzerine lityum ile bileşik yapabilen $\mathrm{Sn}-\mathrm{Cu}$ alaşım matrisli çok duvarlı karbon nanotüp (ÇDKNT) takviyeli kompozit anotların elektrolitik kaplama ile üretimi gerçekleştirilmiştir. Kompozit anotların fiziksel ve elektrokimyasal özelliklerine etkisini ortaya koymak amaciyla akım yoğunluğunun etkisi araştırılmış olup, kesikli akım (pulse current) yöntemi ile $\mathrm{Sn}-\mathrm{Cu}$ alaşım esaslı çok duvarlı karbon nanotüp takviyeli elektrokompozit anotların üretimi gerçekleştirilmiştir.

\section{DENEYSEL ÇALIŞMALAR}

$\mathrm{Bu}$ çalışmada, Sn-Cu / KNT kompozitleri, bir pirofosfat banyosundaki bakır altlık üzerine kesikli akım elektrolitik kaplama ile gerçekleştirildi. Kaplama üretiminde kesikli akım kompozit kaplamada akım yoğunluğunun etkisi araştırıldı. Sn-Cu / KNT kompozitleri üretmek için kullanılan elektrolitik kaplama banyosunun bileşenleri ve çalışma koşulları Tablo 1'de verilmektedir. 
Tablo 1. Kesikli akım (PC) ile Sn-Cu/KNT kompozit kaplama üretiminde kullanılan banyo bileşimi ve çalışma koşulları.

\begin{tabular}{|l|c|c|c|c|}
\hline & \multicolumn{4}{|c|}{ A } \\
\hline Banyo kodu & A1 & A2 & A3 & A4 \\
\hline Kalay klorür $\left(\mathrm{SnCl}_{2}\right)(\mathrm{g} / \mathrm{L})$ & 50 & 50 & 50 & 50 \\
\hline Bakır sülfat (CuSO 4$)(\mathrm{g} / \mathrm{L})$ & 30 & 30 & 30 & 30 \\
\hline Potasyum difosfat (g/L) & 150 & 150 & 150 & 150 \\
\hline Gelatin (g/L) & 1 & 1 & 1 & 1 \\
\hline KNT konsantrasyonu (g/L) & 5 & 5 & 5 & 5 \\
\hline Kaplama süresi (dakika) & 5 & 5 & 5 & 5 \\
\hline pH $\pm 0,4$ & 4,5 & 4,5 & 4,5 & 4,5 \\
\hline Pik Akım yoğunluğu (mAcm- $\left.{ }^{2}\right)$ & $\underline{\mathbf{2 0}}$ & $\underline{\mathbf{4 0}}$ & $\underline{\mathbf{6 0}}$ & $\underline{\mathbf{8 0}}$ \\
\hline Sicaklık ( $\left.{ }^{\circ} \mathrm{C}\right)$ & 30 & 30 & 30 & 30 \\
\hline İş Çevrimi \% & 50 & 50 & 50 & 50 \\
\hline Frekans Mhz & 100 & 100 & 100 & 100 \\
\hline
\end{tabular}

Bakır altlık 2 dakika boyunca \% $25 \mathrm{H} 2 \mathrm{~S} 04$ solüsyonunda da aktive edilmiştir. Kaplama banyosu sürekli olarak manyetik ve ultrasonik olarak karıştırıldı. Ultrasonik olarak karıştırma işlemi UP400S cihazi ile $20 \mathrm{KHz}$ ve $60 \mathrm{~W}$ güç şartlarında gerçekleştirildi. Kesikli akım (PC) kullanılarak gerçekleştirilen kompozit kaplama çalışmalarında akım yoğunluğunun etkisi incelenmiş olup, 20, 40, 60 ve $80 \mathrm{mAcm}-2$ olmak üzere üç farklı akım yoğunluğunda kompozit kaplamalar üretildi. KNT'lerin kaplama tabakasındaki dağılımını arttırmak için, KNT'lerin yüzey işlemi, bir nitrik asit / sülfürik asit çözeltisi karışımı kullanılarak gerçekleştirildi. Ardından, KNT'ler elektrolit içinde dağıtıldı. Elektrolitik kaplamadan sonra, kompozit kaplamaların yüzey morfolojisini incelemek için taramalı elektron mikroskopu (JEOL-JSM 6060 LV) kullanıldı. Üretilen kompozit anotların faz yapılarını incelemek için, Rigaku marka
D/MAX/2200/PC model X-1şını cihazı ile XRD analizi yapılmıştır. Üretilen kompozit malzemeler CR2016 buton pilinde anot olarak kullanıldı ve elektrokimyasal olarak test edildi.

\section{BULGULAR VE TARTIŞMA}

Tablo 1'de bileşimi verilen elektrolitik kaplama banyosunda diğer parametreler sabit tutularak, kesikli akım (PC) yöntemiyle farklı pik akım yoğunluklarında üretilen anot malzemelerindeki fiziksel özelliklerin değişimi incelenmiştir. A1, A2, A3 ve A4 kodlu banyolarda değişken olarak sirası ile 20, 40, 60 ve $80 \mathrm{~mA} / \mathrm{cm} 2$ olacak şekilde dört farklı pik akım yoğunluğu kullanılmıştır. Farklı pik akım yoğunluğunda üretilen Sn$\mathrm{Cu} / \mathrm{KNT}$ kompozit anotlara SEM çalışması yapılmış ve elde edilen mikroyapı görüntüleri Şekil 1'de verilmiştir. 

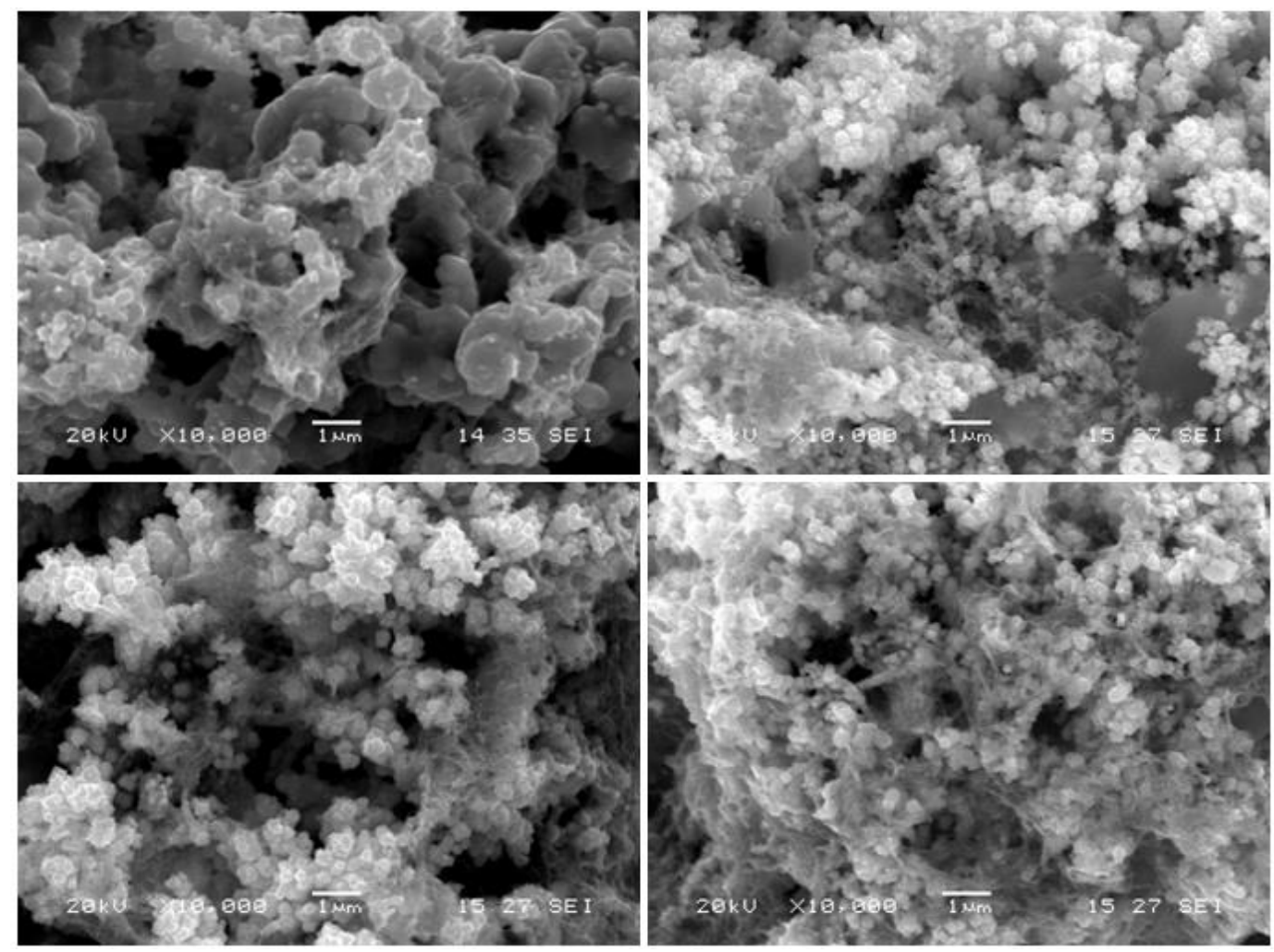

Şekil 1. Kesikli akım (PC) ile üretilen Sn-Cu/KNT kompozit kaplamalara pik akım yoğunluğunun etkisi; (SEM) görüntüleri x10000, SEI); a) $20 \mathrm{~mA} / \mathrm{cm} 2$ b) $40 \mathrm{~mA} / \mathrm{cm} 2$ c) $60 \mathrm{~mA} / \mathrm{cm} 2$ ve d) $80 \mathrm{~mA} / \mathrm{cm} 2$

Şekil 1'de verilen ve pik akım yoğunluğunun etkisi incelenen $\mathrm{Sn}-\mathrm{Cu} / \mathrm{KNT}$ kompozit anotlara ait SEM görüntüleri incelendiğinde artan pik akım yoğunluğu ile birlikte kaplama tabakası içerisine giren KNT miktarının arttığı anlaşılmaktadır. Artan KNT miktarının alaşım matrisli KNT takviyeli elektrotların elektrokimyasal olarak performansını etkileyeceği bilinmektedir.

Artan akım yoğunluğu ile kaplama tabakasına giren KNT miktarının artması elektroforetik gücün artmasından kaynaklanmaktadır [21]. Ayrıca artan akım yoğunluğu ile birlikte kaplama tabakasına biriken (indirgenen metal) kalay ve bakır miktarlarında da artış söz konusudur.

Artan akım yoğunluğu ile birlikte aktif madde olan kalay miktarının artması ile üretilen elektrotların elektrokimyasal performansları da direkt olarak etkilenmektedir. Bunun yanı sıra artan akım yoğunluğu ile alaşım matrisin tane boyutu da etkilenmekte ve akım yoğunluğunun artışı ile azalmaktadır. Yüksek akım yoğunluklarında taneciklerin büyümesinden ziyade yeni tanecik oluşumu meydana gelmektedir $[22,23]$. Ayrıca difüzyon kontrollü proseslerde oluşan taneciklerin daha küçük olduğu bilinmektedir [24]. Tane boyutundaki azalmanın bir başka nedeni de artan akım yoğunluğu ile disperse KNT'lerin miktarının artmasıdır. Kaplama tabakasına giren KNT'ler heterojen çekirdekleyici olarak davranmakta ve kalay-bakır çekirdeklerinin yüzey alanlarını azaltarak çok daha ince boyutta çekirdeklerin oluşmasına yol açmaktadır. Alaşım matrisli kompozit anotta $\mathrm{Cu} 6 \mathrm{Sn} 5$ metallerarası bileşiğin oluşumunu göstermek amacıyla kesikli akım (PC) yöntemiyle ve $80 \mathrm{~mA} / \mathrm{cm} 2$ pik akım yoğunluğu ile üretilen $\mathrm{Sn}-\mathrm{Cu} / \mathrm{KNT}$ kompozit elektrota XRD analizi yapılmış ve XRD analiz sonucu Şekil 2'de verilmiştir. 


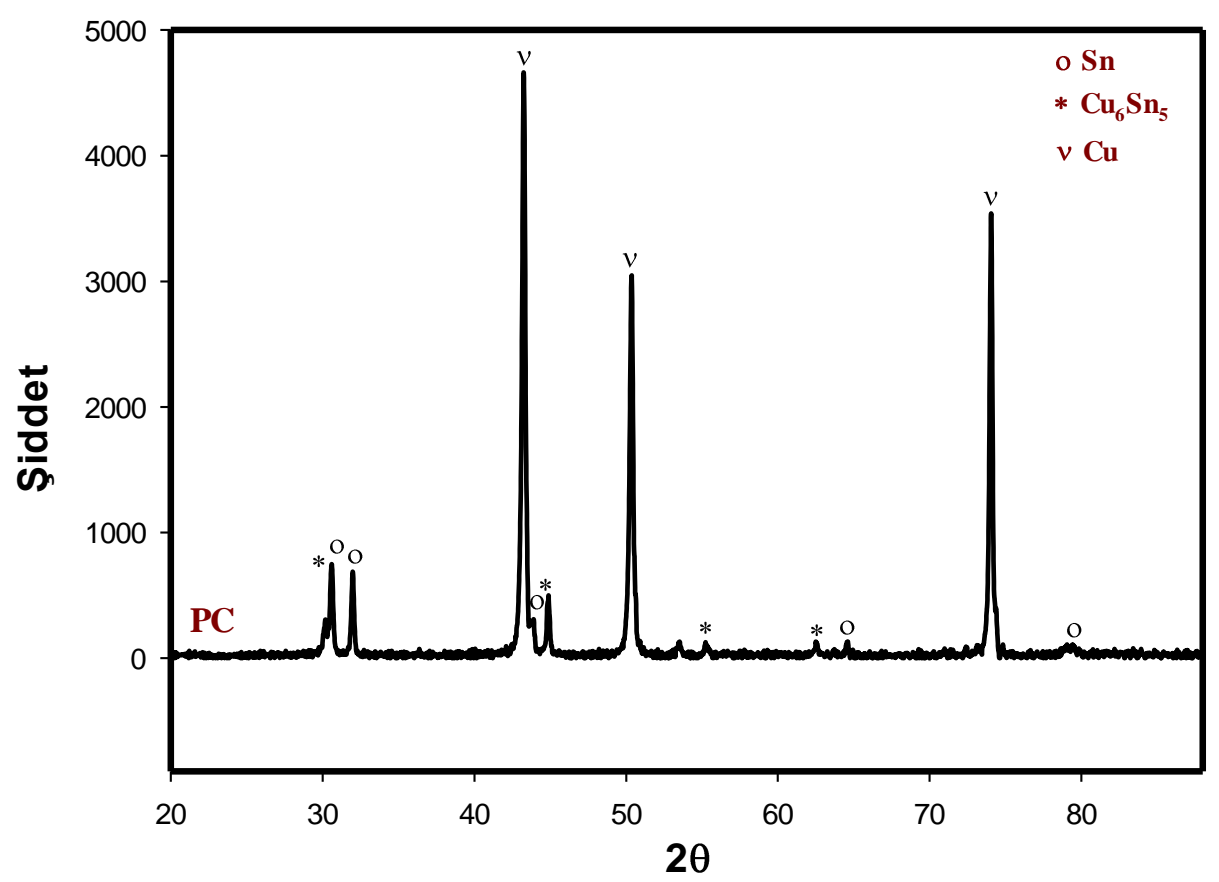

Şekil 2. Kesikli akım (PC) yöntemiyle ve $80 \mathrm{~mA} / \mathrm{cm}^{2}$ pik akım yoğunluğunda üretilen $\mathrm{Sn}-\mathrm{Cu} / \mathrm{KNT}$ kompozit elektrottan elde edilen X-1şını kırınım örgüleri (XRD).

Şekil 2'de görüldüğü gibi $80 \mathrm{~mA} / \mathrm{cm} 2$ pik akım yoğunluğu ile üretilen $\mathrm{Sn}-\mathrm{Cu} / \mathrm{KNT}$ kompozit elektrottan elde edilen XRD pikleri numunede kalay ve bakır yanında $\mathrm{Cu} 6 \mathrm{Sn} 5$ fazınında varlığını ortaya koymuştur. Kompozit anottan alınan XRD analizinde KNT'e ait pike rastlanmamıştır. Bunun nedeni ise yapı içerisinde yer alan bir element yada bileşikten ağırlıkça $\% 5$ 'ten daha az bir miktarda olması durumunda XRD analizi ile tespitinin çok kolay olmamasıdır [25]. Bakıra ait pik şiddetinin yüksek olması sadece kaplama tabakasında yer alan bakır içeriğinden değil aynı zamanda altlı̆ğn da bakır olmasından kaynaklanmaktadır. $2 \square \square 44,4,55,3$ ve $62,5^{\prime}$ 'lik değerlerinde Cu6Sn5 intermetalik fazının pikleri görülmektedir. $\mathrm{Sn}-\mathrm{Cu}$ alaşımlarında $\mathrm{Cu} 3 \mathrm{Sn}$ benzeri bileşikler de oluşabilmekte, fakat elektrokimyasal performans bakımından Cu6Sn5 bileşiği daha yüksek performans sergilemektedir. Bilindiği gibi Cu6Sn5 intermetalik fazının oluşumu, Sn-Cu/KNT kompozit elektrotun kapasite korunumunu ve kararlılığını arttırmaktadır. İntermetalik faz oluşumu ile kapasite kararlılığını ve korunumunu arttırmaya yönelik yapılmış alaşım matrisli elektrot çalışmaları söz konusu olup, oluşan metallerarası bileşiğin söz konusu avantajları da ortaya konmuştur [6, 7].
Geçmiş yıllarda araştırmacılar tarafindan yapılan çalışmalar göstermiştir ki saf kalay anotların şarj ve deşarj esnasında hacimsel artış ile pulverize olmasi veya topaklanmalarından kaynaklanan sebeplerden dolayı düşük elektrokimyasal performans sergilemektedirler [26]. Saf kalay esaslı elektrotları bu tür etkilerle pil performanslarının düşük çevrim ömrüne sahip olmasindan dolayı, bu tür elektrotların performanslarını arttırmak amacına yönelik pek çok çalışma türünden ve son yılların en önemli konu başlıklarından biri alaşım matrisli ve KNT takviyeli kompozit anotların üretilmesi olmuştur. $\mathrm{Bu}$ çalışmada da bu amaca yönelik olarak Sn$\mathrm{Cu} / \mathrm{KNT}$ anotlar kesikli akım (PC) yöntemiyle üretilmiş ve pik akım yoğunluğunun etkisi araştırılmıştır. Artan pik akım yoğunluğunun kaplama tabakası içerisine gömülen KNT miktarının yanı sıra alaşım matris ile oluşan Cu6Sn5 intermetalik fazını da etkilediğinden dolayı elektrotun pil performansını olumlu yönde etkileyeceği makul bir düşünce olup, bu amaçla üretilen kompozit elektrotun pik akım yoğunluğuna bağlı olarak sergilemiş olduğu elektrokimyasal performansı tespit edilmiş, elde edilen kapasite-çevrim sayısı grafiği Şekil 3'de verilmiştir. 


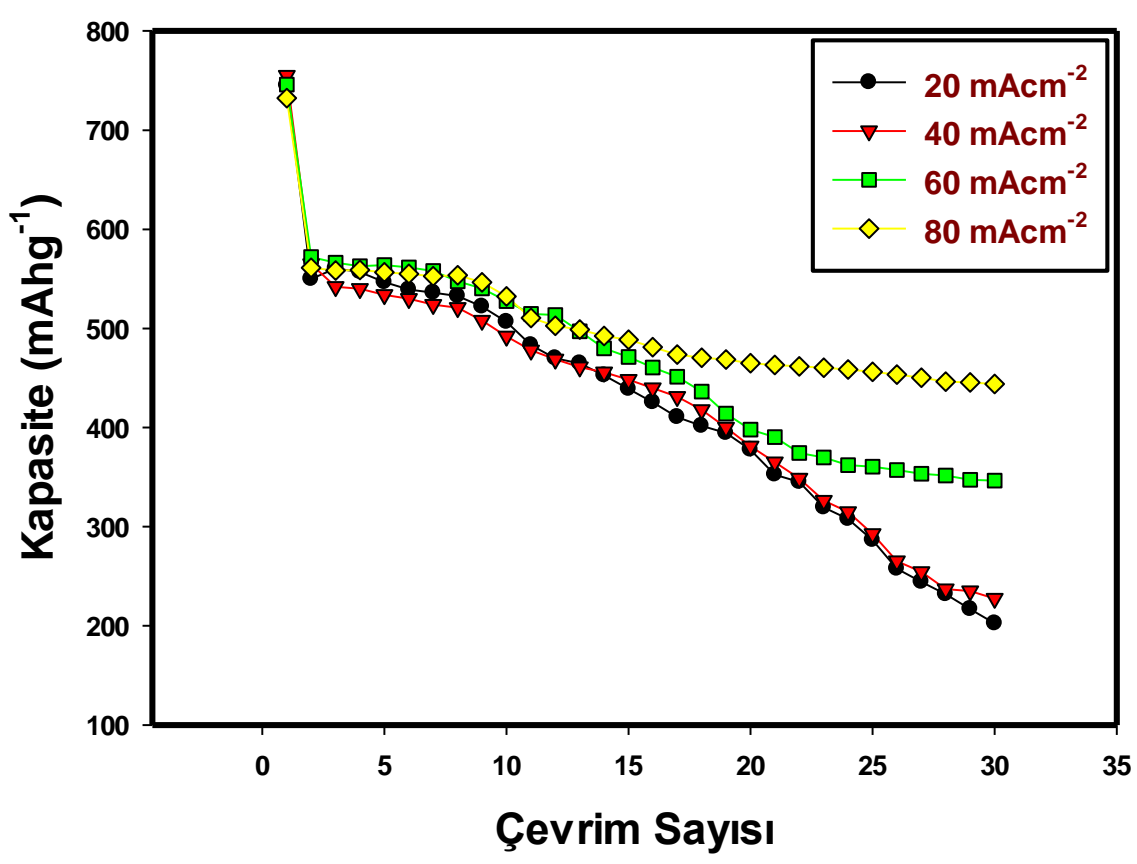

Şekil 3. Kesikli akım (PC) yöntemiyle ve farklı pik akım yoğunluklarında üretilen $\mathrm{Sn}-\mathrm{Cu} / \mathrm{KNT}$ kompozit elektrotların elektrokimyasal performansını gösteren Kapasite-Çevrim Sayısı grafiği.

Kesikli akım (PC) yöntemiyle üretilen ve pik akım yoğunluğunun etkisi incelenen $\mathrm{Sn}-\mathrm{Cu} / \mathrm{KNT}$ kompozit anotlardan elde edilen kapasite-çevrim sayısı eğrisine göre; akım yoğunluğunun artışına bağlı olarak elektrot performansında çok büyük bir iyileşme olduğunu söylemek zordur. Fakat akım yoğunluğundaki artışa bağlı olarak kapasite değerlerinde bir artış söz konusudur. Pik akım yoğunluğunun etkisi kapasite değerlerinin artışının yanında elektrotun yani anotun davranış olarak daha kararlı hale gelmesiyle kendini göstermektedir. Özellikle 60 ve $80 \mathrm{~mA} / \mathrm{cm} 2 \mathrm{akım}$ yoğunluğu ile üretilen anotlarda kapasitenin ve kapasite kararlılığının diğerlerine göre daha yüksek olduğu anlaşılmaktadır. Pil performansını değerlendirmede sadece yüksek kapasite değerlerinin önemli olmadığı göz önünde bulundurulacak olursa, hatta yüksek kapasite değerlerinden ziyade kapasite kararlılığının daha önemli bir davranış olduğu düşünülürse artan pik akım yoğunluğunun pil performansına önemli bir etki yaptığı anlaşılmaktadır. Buradan hareketle en kararlı elektrot davranışı sergileyen pilin en yüksek akım yoğunluğu olan $80 \mathrm{~mA} / \mathrm{cm} 2$ ile üretilen $\mathrm{Sn}-\mathrm{Cu} / \mathrm{KNT}$ kompozit elektrottan elde edildiği net olarak anlaşılmaktadır. Burada artan akım yoğunluğu ile kararlı elektrot davranışının artmasının birkaç sebebi söz konusu olabilir. Artan akım yoğunluğu ile Şekil 1.'de de kısmen de olsa görüldüğ̈ gibi kaplama tabakasına giren KNT miktarı bir miktar artmış, bu artış ile alaşımlama ve dealaşımla sırasındaki hacimsel artı̧ ve azalmalarda ihtiyaç duyulan homojen porozite dağılımını sağlanmış ve elektrotun bozulmasının önüne geçilmiştir. Ayrıca KNT'ler kalayın hacimsel genleşmesini önlemede tampon görevi de görerek kapasitenin daha kararlı hale gelmesini sağlamaktadır [27, 28].

Artan akım yoğunluğu ile kapasitenin kararlı hale gelmesinde etken olan bir diğer sebep de intermetalik faz oluşumudur. Şekil 2.'de verilen XRD analizinden $\mathrm{Cu} 6 \mathrm{Sn} 5$ intermetalik fazının oluşumu görülmektedir. Literatürde verilen alaşım matrisli elektrot oluşturma sebeplerinin başında intermetalik faz oluşumu ile kapasite kararlılığı sağlanması gösterilmektedir [7-10]. Metallerarası bileşik oluşumu ile elektrotun kararlığı ve çevrim ömrü artırılmaktadır [8-12, 27, 29]. Bunun nedeni olarak yapıda az miktarda da olsa oluşan ve homojen dağılan intermetalik faz içindeki kalayın Li ile reaksiyon verme aktifliği serbest kalaya göre azaldığından, alaşımlama ve dealaşımlama sırasındaki hacimsel değişimleri tamponlamada da rol almasından kaynaklandığı ileri sürülebilir. Bu sonuçlar 1şığında artan pik akım yoğunluğu ile kararlı elektrot davranışının sebepleri olarak artan intermetalik faz oluşumu (Cu6Sn5) ve kaplama tabakasina giren KNT miktarı gösterilebilir.

$\mathrm{Bu}$ sebepler dışında artan akım yoğunluğu ile kaplamanın tane boyutu da azaldığından dolayı kapasitede bir miktar artış söz konusu olabilir. Tane boyutunun küçülmesine bağlı olarak reaksiyonlar için daha geniş bir yüzey alanı ortaya çıktığından, daha fazla kalay daha kolay bir şekilde Li ile reaksiyona girerek daha yüksek kararl1 kapasitenin elde edilmesine neden olmaktadır. Ayrıca artan akım yoğunluğu ile 
indirgenen metal miktarı da (özellikle aktif metal olan Sn) arttığından dolayı kapasitede artış söz konusu olmaktadır.

Kesikli akım (PC) yöntemiyle üretilen ve pik akım yoğunluğunun etkisi incelenen $\mathrm{Sn}-\mathrm{Cu} / \mathrm{KNT}$ kompozit anotların elektrokimyasal performanslarını daha net ortaya koyabilmek amacıyla voltaj-kapasite eğrileri verilmiş olup, 20 $\mathrm{mA} / \mathrm{cm} 2$ pik akım yoğunluğu ile üretilen Sn$\mathrm{Cu} / \mathrm{KNT}$ kompozit anota ait voltaj-kapasite eğrisi Şekil 4'de gösterilmektedir.

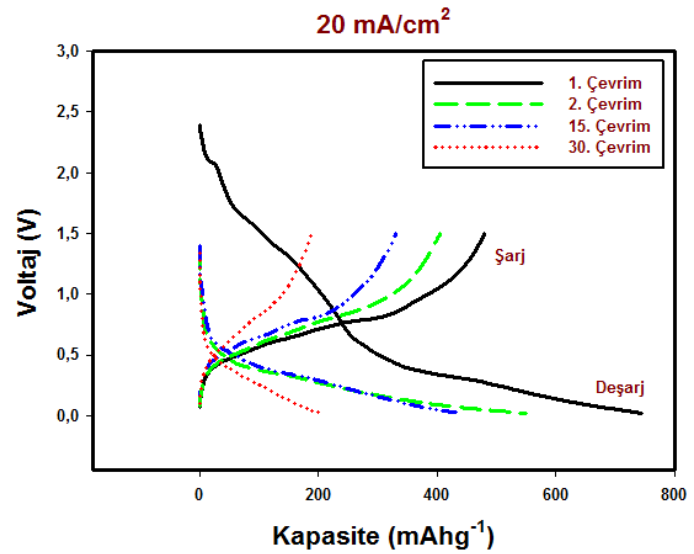

Şekil 4. Kesikli akım (PC) yöntemiyle ve 20 $\mathrm{mA} / \mathrm{cm} 2$ pik akım yoğunluğu ile üretilen $\mathrm{Sn}$ $\mathrm{Cu} / \mathrm{KNT}$ kompozit elektrota ait Voltaj-Kapasite eğrisi.

Kompozit anotlar kullanılarak hazırlanan pil test hücreleri $0,02-1,5 \mathrm{~V}$ arasında 30 çevrim boyunca sabit akım yoğunluğu ile test edilmişlerdir. Kesikli akım (PC) yöntemiyle ve $20 \mathrm{~mA} / \mathrm{cm} 2$ pik akım yoğunluğu ile üretilen $\mathrm{Sn}-\mathrm{Cu} / \mathrm{KNT}$ kompozit elektrota ait voltaj-kapasite eğrilerinde 1., 2., 15. ve 30. çevrim değerleri için şarj ve deşarj kapasite değerleri görülmektedir. Grafik incelendiğinde artan çevrim sayısı ile kapasite değerlerinin azaldığı net olarak anlaşılmaktadır. İlk çevrim sonrası elde edilen deşarj kapasite değeri $745 \mathrm{mAh} / \mathrm{g}$ olarak tespit edilirken, artan çevrim sayılarına bağlı olarak deşarj kapasitesi değerinin 2., 15 . ve 30 . çevrim sonunda sırasıyla 550,439 ve $202 \mathrm{mAh} / \mathrm{g}$ değerlerine kadar düştüğü anlaşılmaktadır. İlk deşarj işlemi sırasında çok yüksek oranda $\mathrm{Li}$ iyonlarının aktif olmasının temel nedeni anot elektrotun kristallerinin boyutunun düşük ve yüzey alanının yüksek olmasıdır [30]. Buradan hareketle 1. çevrim ile 30. çevrim arasındaki kapasite değerleri karşılaştırıldığında deşarj kapasitesi korunumunun \% 27,1 olduğu anlaşılmaktadır. 2. 15. ve 30. çevrim değerleri için (artan çevrim sayıs ile) sırasıyla kapasite korunumunun $\% 73,8$ $\% 58,9$ ve $\% 27,1$ olarak elde edildiği ve sürekli azaldığı anlaşılmaktadır. Kapasite korunumunun özellikle 30. çevrim sonunda \% 27,1 değerlerine kadar düşmüş olması kompozit anotun elektrokimyasal kaplama ile üretilmesi sırasında yeterli aktif madde miktarının birikmediğine, yeterli karbon nanotüpün yap1 içerisine giremediğine ya da kapasite korunumunu sağlayabilecek düzeyde intermetalik fazın oluşamadığına bağlanabilir. Tüm bu sebeplerden dolayı en düşük pik akım yoğunluğu olan 20 $\mathrm{mA} / \mathrm{cm} 2$ pik akım yoğunluğunda düşük kapasite değerleri ve düşük kararlılığa sahip elektrot elde edilmiştir. Bir diğer pik akım yoğunluğu parametresi olan $40 \mathrm{~mA} / \mathrm{cm} 2$ pik akım yoğunluğu ile üretilen $\mathrm{Sn}-\mathrm{Cu} / \mathrm{KNT}$ kompozit anota ait voltajkapasite eğrileri çevrim sayısına bağlı olarak Şekil 5'de verilmiştir.

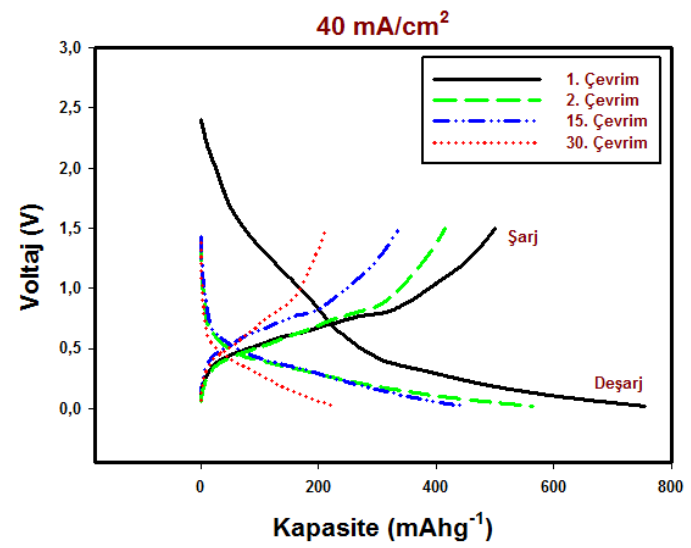

Şekil 5. Kesikli akım (PC) yöntemiyle ve 40 $\mathrm{mA} / \mathrm{cm} 2$ pik akım yoğunluğu ile üretilen $\mathrm{Sn}$ $\mathrm{Cu} / \mathrm{KNT}$ kompozit elektrota ait Voltaj-Kapasite eğrisi.

Şekil 5'de verilen voltaj-kapasite eğrisi 40 $\mathrm{mA} / \mathrm{cm} 2$ pik akım yoğunluğu ile üretilen kompozit elektrota aittir. Artan çevrim sayısına bağlı olarak şarj ve deşarj kapasite değerlerinin görüldüğü grafikten, artan çevrim sayısının kapasite değerlerinin düşmesine neden olduğu anlaşılmaktadır. Artan çevrim sayısı ile sırasıyla deşarj kapasitesi değerleri 1. çevrim sonunda 755 $\mathrm{mAh} / \mathrm{g}, 2$. çevrim sonunda $565 \mathrm{mAh} / \mathrm{g}, 15$. çevrim sonunda $448 \mathrm{mAh} / \mathrm{g}$ ve 30 . çevrim sonunda ise $227 \mathrm{mAh} / \mathrm{g}$ olarak elde edilmiştir. Çevrim sayısına bağlı olarak kapasite korunumu değerleri hesaplandığında 2., 15 . ve 30 . çevrim için deşarj kapasitesi korunumu değerleri sırasıyla $\% 74,8 \%$ 59,3 ve \% 30,06 olarak hesaplanmıştır. Çıkan sonuçlardan da anlaşılabileceği gibi artan çevrim sayısı ile kapasite korunumu azalmakta olup, 30. çevrim sonunda yaklaşı $\% 30$ değerlerine kadar düşmektedir. $40 \mathrm{~mA} / \mathrm{cm} 2$ pik akım yoğunluğu ile üretilen elektrotun 30 . çevrim sonundaki kapasite korunumu yaklaşık olarak \% 30 iken şekil 4'de verilen ve $20 \mathrm{~mA} / \mathrm{cm} 2$ pik akım yoğunluğu ile üretilen elektrotun 30 . çevrim sonundaki kapasite korunumu ise \% 27,1'dir. Pik akım yoğunluğu 
açısından $20 \mathrm{~mA} / \mathrm{cm} 2$ pik akım yoğunluğu değerinden $40 \mathrm{~mA} / \mathrm{cm} 2$ pik akım yoğunluğu değerine çıkılarak yapılan elektrot üretiminde 30 . çevrim sonundaki kapasite korunumunun bir miktar arttığı anlaşılmaktadır. Bu artış düzeyinin düşük olması da akım yoğunluğunun $(40 \mathrm{~mA} / \mathrm{cm} 2)$ kapasite artışına yeterli katkısının olmadığını ortaya koymaktadır.

$\mathrm{Bu}$ açıdan daha yeterli artışın sağlanabildiği şartları görme adına akım yoğunluğu biraz daha artırılarak $(60 \mathrm{~mA} / \mathrm{cm} 2)$ çalışmalar yapılmıştır. 60 $\mathrm{mA} / \mathrm{cm} 2$ akım yoğunluğu ile üretilen $\mathrm{Sn}-\mathrm{Cu} / \mathrm{KNT}$ kompozit anota ait Voltaj-Kapasite eğrisi Şekil 6 'da verilmiştir. $60 \mathrm{~mA} / \mathrm{cm} 2$ akım yoğunluğu ile üretilen $\mathrm{Sn}-\mathrm{Cu} / \mathrm{KNT}$ kompozit anot elektrokimyasal performans olarak bu değerden düşük olan pik akım yoğunluğu değerlerine kıyasla daha üstün bir performans gösterdiği elde edilen voltaj-kapasite grafiğinden net olarak anlaşılmaktadır. $60 \mathrm{~mA} / \mathrm{cm} 2$ akım yoğunluğu ile üretilen $\mathrm{Sn}-\mathrm{Cu} / \mathrm{KNT}$ kompozit elektrotun voltajkapasite eğrisi dikkatli bir şekilde incelendiğinde artan çevrim sayısı ile kapasite değerlerinin düştüğü fakat meydana gelen düşüşün önceki pik akım yoğunluğu değerlerine oranla çok daha düşük oranda kaldığı görülmektedir.

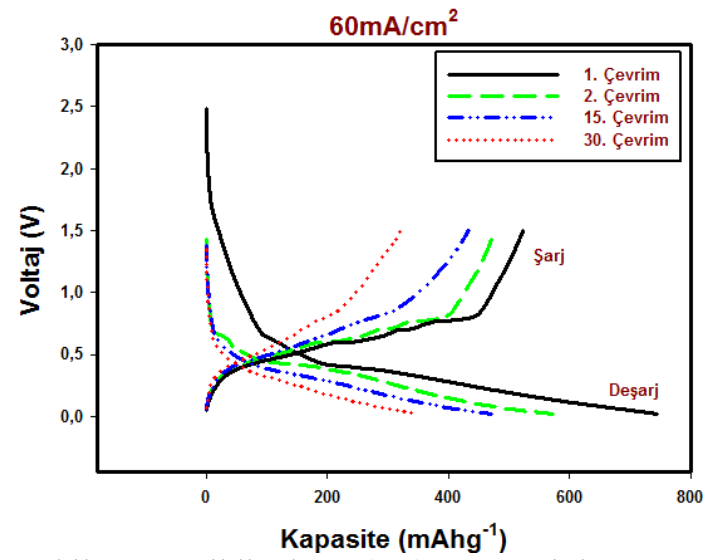

Şekil 6. Kesikli akım (PC) yöntemiyle ve 60 $\mathrm{mA} / \mathrm{cm} 2$ pik akım yoğunluğu ile üretilen Sn$\mathrm{Cu} / \mathrm{KNT}$ kompozit elektrota ait Voltaj-Kapasite eğrisi.

Artan çevrim sayısına bağlı olarak elde edilen kapasite değerleri sirasıyla $746 \mathrm{mAh} / \mathrm{g}, 572$ $\mathrm{mAh} / \mathrm{g}, 471 \mathrm{mAh} / \mathrm{g}$ ve $346 \mathrm{mAh} / \mathrm{g}$ olarak elde edilmiştir. Elde edilen bu değerler göz önüne alındığında 30. çevrim sonunda elde edilen 346 $\mathrm{mAh} / \mathrm{g}$ 'lık kapasite değerinin bundan önceki 2 pik akım yoğunluğu parametresinden de yüksek olduğu görülmektedir. 30. çevrim sonunda elde edilen deşarj kapasitesi açısından yapılacak karşılaştırmada $60 \mathrm{~mA} / \mathrm{cm} 2$ pik akım yoğunluğu ile üretilen kompozit elektrotun kapasite değerinin 20 ve $40 \mathrm{~mA} / \mathrm{cm} 2$ pik akım yoğunluğu ile üretilen elektrotlardan daha yüksek olduğu net olarak anlaşılmaktadır. Kapasite korunumu açısından bakıldığında ise 2 . 15 . ve 30 . çevrim sonunda artan çevrim sayısına bağlı olarak deşarj kapasitesi korunumu değerlerinin 2. çevrim için $\% 76,6,15$. çevrim için $\% 63,2$ ve 30 . çevrim için ise $\% 46,4$ olduğu tespit edilmiştir. Elde edilen bu değerler 1şı̆̆ında $20 \mathrm{~mA} / \mathrm{cm} 2$ pik akım yoğunluğundan $60 \mathrm{~mA} / \mathrm{cm} 2$ pik akım yoğunluğuna çıkıldığında kapasite korunumunun da yaklaşık \% 27 değerlerinden \% 46,4 değerlerine kadar çıktığı görülmektedir. Akım yoğunluğunun kapasite korunumuna önemli bir etkisi olduğu gözlendiğinden elektrot üretimi sırasında çalışılan akım yoğunluğunun biraz daha artırılması hususunda oluşan kanaat sonucu 80 $\mathrm{mA} / \mathrm{cm} 2$ akım yoğunluğu değerinde de elektrot üretilmiştir.

En yüksek akım yoğunluğu değeri olan 80 $\mathrm{mA} / \mathrm{cm} 2$ pik akım yoğunluğu ile üretilen Sn$\mathrm{Cu} / \mathrm{KNT}$ kompozit elektrota ait voltaj-kapasite eğrisi Şekil 7'de gösterilmektedir.

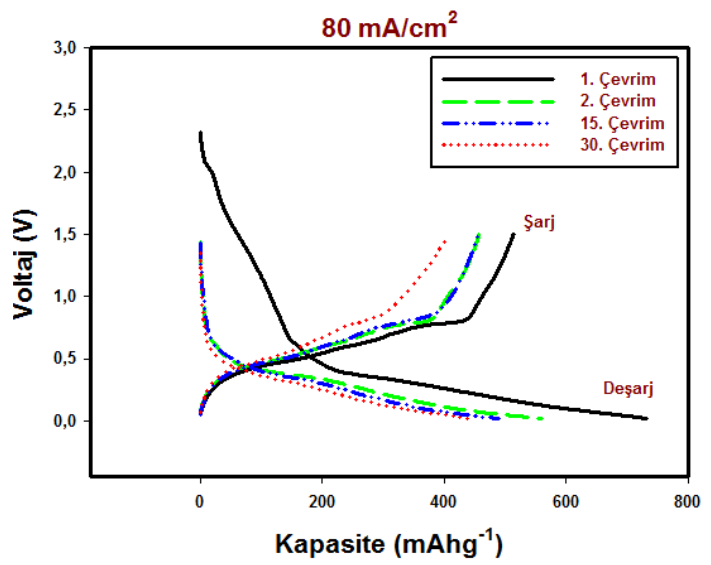

Şekil 7. Kesikli akım (PC) yöntemiyle ve 80 $\mathrm{mA} / \mathrm{cm} 2$ pik akım yoğunluğu ile üretilen Sn$\mathrm{Cu} / \mathrm{KNT}$ kompozit elektrota ait Voltaj-Kapasite eğrisi.

En yüksek akım yoğunluğu değeri olan 80 $\mathrm{mA} / \mathrm{cm} 2$ pik akım yoğunluğu ile üretilen $\mathrm{Sn}$ $\mathrm{Cu} / \mathrm{KNT}$ kompozit elektrota ait voltaj-kapasite eğrisi göstermektedir ki, artan pik akım yoğunluğu ile üretilen elektrotlarda pik akım yoğunluğundaki artışa bağlı olarak kapasite kayıplarında önemli ölçüde azalma sağlanmıştır. Yapilan inceleme sonucunda $80 \mathrm{~mA} / \mathrm{cm} 2$ pik akım yoğunluğu ile üretilen $\mathrm{Sn}-\mathrm{Cu} / \mathrm{KNT}$ kompozit anot artan çevrim sayısına bağlı olarak kapasite kaybı yaşamakta fakat bu kayıp diğer pik akım yoğunluğu parametreleri ile karşılaştırıldığında çok daha düşük kalmaktadır. Elde edilen deşarj kapasitesi değerleri açısından bakıldığında artan çevrim sayısına bağlı olarak 1 . çevrim sonunda elde edilen deşarj kapasitesi 732 
$\mathrm{mAh} / \mathrm{g}, 2$. çevrim sonunda $561 \mathrm{mAh} / \mathrm{g}, 15$. çevrim sonunda $488 \mathrm{mAh} / \mathrm{g}$ ve 30 . çevrim sonunda ise $444 \mathrm{mAh} / \mathrm{g}$ olarak elde edilmiştir. Bu değerler de göstermektedir ki artan akım yoğunluğuna bağlı olarak 30. çevrim sonunda en yüksek deşarj kapasitesi değeri $80 \mathrm{~mA} / \mathrm{cm} 2$ pik akım yoğunluğu ile üretilen $\mathrm{Sn}-\mathrm{Cu} / \mathrm{KNT}$ kompozit elektrottan elde edilmiştir. Kapasite korunumu açısından yapılan incelemede ise artan çevrim sayısına bağlı olarak 2. çevrim sonunda elde edilen deşarj kapasitesi korunumu $\% 76,6,15$. çevrim sonunda $\% 66,7$ ve 30. çevrim sonunda ise $\% 60,6$ olarak tespit edilmiştir.

Elde edilen sonuçlardan da anlaşılmaktadır ki artan akım yoğunluğu elektrotun hem kapasitesini hem de kapasite korunumunu arttırmaktadır. Sonuçlar dikkatli bir şekilde incelendiğinde artan pik akım yoğunluğunun kompozit elektrotun kararlı davranışını önemli ölçüde etkileyen bir parametre olduğu anlaşılmaktadır. Kapasite korunumu açısından yapılacak karşılaştırma neticesinde 20,40, 60 ve $80 \mathrm{~mA} / \mathrm{cm} 2$ pik akım yoğunluğu değerleri için 30 . çevrim sonunda elde edilen kapasite korunumu değerleri sirasıyla \% $27, \% 30, \%$ 46,4 ve \% 60,6 olarak elde edilmektedir. $\mathrm{Bu}$ değerlerde göstermektedir ki artan akım yoğunluğuna bağlı olarak kapasite korunumu artmaktadır. Elde edilen kapasite değerleri açısından bir karşılaştırma yapılacak olursa yine artan akım yoğunluğuna bağlı olarak 30. çevrim sonundaki kapasite değerleri sırasıyla 202, 227, 346 ve $444 \mathrm{mAh} / \mathrm{g}$ olarak ortaya çıkmaktadır. Tablo 2'de farklı pik akım yoğunluklarında üretilen $\mathrm{Sn}-\mathrm{Cu} / \mathrm{KNT}$ kompozit anotlara ait deşarj kapasite değerleri ve kapasite korunum yüzdeleri yer almaktadır.

Tablo 2. Kesikli akım (PC) ile farklı pik akım yoğunluklarında üretilen Sn-Cu/KNT kompozit elektrotların deşarj kapasiteleri ve kapasite korunum değerleri.

\begin{tabular}{|c|c|c|c|c|c|c|c|c|}
\hline Sn- & & \multicolumn{4}{|c|}{ Spesifik Deşarj Kapasitesi (mAhg-1) } & \multicolumn{3}{|c|}{ Kapasite Korunumu (\%) } \\
\hline $\begin{array}{l}\text { Pik Akım } \\
\text { yoğunluğu }\end{array}$ & & $\begin{array}{c}\text { 1.Çevri } \\
\mathrm{m}\end{array}$ & $\begin{array}{c}\text { 2.Çevri } \\
\mathrm{m}\end{array}$ & $\begin{array}{c}\text { 15. Çevri } \\
\mathrm{m}\end{array}$ & $\begin{array}{c}\text { 30.Çevri } \\
\text { m }\end{array}$ & $\begin{array}{c}2 . \\
\text { Çevri } \\
\text { m }\end{array}$ & $\begin{array}{c}15 . \\
\text { Çevri } \\
\text { m }\end{array}$ & $\begin{array}{c}30 . \\
\text { Çevrim }\end{array}$ \\
\hline $20 \mathrm{mAcm}^{-2}$ & & 745 & 550 & 439 & 202 & 73,8 & 58,9 & 27,1 \\
\hline $40 \mathrm{mAcm}^{-2}$ & & 755 & 565 & 448 & 227 & 74,8 & 59,3 & 30,06 \\
\hline $60 \mathrm{mAcm}^{-2}$ & & 746 & 572 & 471 & 346 & 76,6 & 63,2 & 46,4 \\
\hline $80 \mathrm{mAcm}^{-2}$ & & 732 & 561 & 488 & 444 & 76,58 & 66,7 & 60,06 \\
\hline Grafit & 330 & & & & & & & \\
\hline Kalay & 990 & & & & & & & \\
\hline
\end{tabular}

Tablo 2'deki sonuçlara genel bakılacak olursa artan akım yoğunluğu ile daha yüksek kapasite değeri ve daha yüksek kapasite korunumu değerleri elde edilebilmektedir. Burada neden daha yüksek akım yoğunluğu değerlerinde çalışma yapılmadığı da akla gelebilir. 1. ve 2 . çevrim sonundaki deşarj kapasite değerlerinin 60 dan $80 \mathrm{~mA} / \mathrm{cm} 2$ çıkıldığında düşme eğilimi göstermesi nedeni iledir. Elde edilen bu kararlı elektrot davranışının sebepleri olarak, artan akım yoğunluğuna bağlı olarak üretilen elektrottaki artan aktif madde (Sn) miktarı, yapı içerisine giren KNT miktar1, yeterli Cu6Sn5 intermetalik faz oluşumu ve azalan tane boyutu gösterilebilir. Aktif madde miktarındaki artışın daha fazla reaksiyon vermesi nedeni ile kapasite değerini arttırması gayet doğal olup, karbon nanotüp miktarının ve Cu6Sn5 fazının oluşumunun da elektrot kararlılığını etkilediği literatürde yapılan çalışmalarla ortaya konmaktadır [7, 9-11, 29,30].
Kapasite değerleri özetlendiğinde artan akım yoğunluğu ile elde edilen kapasite değeri en düşük akım yoğunluğu $(20 \mathrm{~mA} / \mathrm{cm} 2)$ için 30 çevrim sonunda $202 \mathrm{mAh} / \mathrm{g}$ iken en yüksek akım yoğunluğunda $444 \mathrm{mAh} / \mathrm{g}$ olmuştur. Sadece pik akım yoğunluğu parametresi ile elde edilen kapasite değeri yaklaşık 2 katına çıkartılmıştır. Kapasite korunumu açısından da benzer bir durum söz konusu olup, \% 27,1 değerlerinden \% 60,06 değerine varan bir artış sağlanmış ve çok daha kararlı bir elektrot davranışı elde edilmiştir.

\section{SONUÇLAR}

$\mathrm{Sn}-\mathrm{Cu} / \mathrm{KNT}$ kompozit kaplamaları farklı akım yoğunlukları kullanılarak kesikli akım kompozit kaplama yöntemi ile başarılı bir şekilde üretilmiştir. Üretilen kaplamalarda kapasite korunumu sağlayan metaller arası bileşik olan Cu6Sn5 fazı elde edilmiştir. Kapasite değerleri ise 
artan akım yoğunluğu ile artış göstermiş olup, elde edilen kapasite değeri en düşük akım yoğunluğu $(20 \mathrm{~mA} / \mathrm{cm} 2)$ için 30 çevrim sonunda $202 \mathrm{mAh} / \mathrm{g}$ iken en yüksek akım yoğunluğunda $444 \mathrm{mAh} / \mathrm{g}$ olmuştur. Kapasite korunumu açısından da benzer bir durum söz konusu olup, \% 27,1 değerlerinden \% 60,06 değerine varan bir artış sağlanmış ve çok daha kararlı bir elektrot davranışı elde edilmiştir.

\section{TEŞEKKÜR}

Bu çalışmaya 111M021 nolu proje kapsamında yapmış oldukları finansal katkılarından dolayı Türkiye Bilimsel ve Teknolojik Araştırma Kurumuna (TÜBİTAK)'a teşekkür ederiz.

\section{KAYNAKLAR}

[1] UYSAL, M., CETINKAYA, T., ALP, A., AKBULUT, H. Active and inactive buffering effect on the electrochemical behavior of $\mathrm{Sn}$ $\mathrm{Ni} / \mathrm{MWCNT}$ composite anodes prepared by pulse electrodeposition for lithium-ion batteries $\mathrm{J}$. Alloys Compd 645:235-242 2015.

[2] ZHU, J., WANG, D., LIU, T., GUO, C. Preparation of Sn-Co-graphene composites with superior lithium storage capability, Electrochimica Acta, 125; 347-353 2014.

[3] POLAT, B.D., ABOUIMRANE, A., SEZGIN, N., KELES, O., AMINE, K. Use of Multilayered $\mathrm{Ni}-\mathrm{Sn}$ and Ni-Sn-C Thin Film Anodes for Lithium-Ion Batteries, Electrochimica Acta, 135; 585-5932014.

[4] UYSAL, M., CETINKAYA, T., ALP, A., AKBULUT, H. Fabrication of Sn-Ni/MWCNT composite coating for Li-ion batteries by pulse electrodeposition: Effects of duty cycle, Applied Surface Science, 334;80-86 2015.

[5] THACKERAY, M. M., Structural Considerations of Layered and Spinel Lithiated Oxides for Lithium Ion Batteries. J. Electrochem. Soc., 142: 2558-2563, 1995.

[6] WEIHHUA, P., XİANGMING, H., JIANGUO, R., CHUNRONG, W., CHANGYIN, J., Electrodeposition of $\mathrm{Sn}-\mathrm{Cu}$ alloy anodes for lithium batteries. Electrochimica Acta, 50:41404145, 2005.

[7] DO H.N., RYOUNG H.K., DONG W.H., HYUK S.K., Electrochemical performances of Sn anode electrodeposited on porous $\mathrm{Cu}$ foam for $\mathrm{Li}$ ion batteries. Electrochimica Acta, 66:126-132, 2012.

[8] GUL, H., UYSAL, M., CETINKAYA, T., GULER, M.O., ALP, A., AKBULUT, H., Preparation of Sn-Co alloy electrode for lithium ion batteries by pulse electrodeposition. Int.J. hydrogen energy, 39:21414-21419, 2014.

[9] QIANLEI, J., RUISHENG X., MENGQIU J.,
Electrochemical performance of $\mathrm{Sn}-\mathrm{Sb}-\mathrm{Cu}$ film anodes prepared by layer-by-layer electrodeposition. Applied Surface Science, 258:3854-3858, 2012.

[10] NORIYUKI, T., RYUJI, O., MASAHISA, F., SHIN, F., MARUO, K., IKUO Y., Study on the anode behavior of $\mathrm{Sn}$ and $\mathrm{Sn}-\mathrm{Cu}$ alloy thinfilm electrodes. J Power Sources, 107:48-55, 2002.

[11] KEPLER, K.D., VAUGHEY, J.T., THACKERAY, M.M., Copperetin anodes for rechargeable lithium batteries: an example of the matrix effect in an intermetallic system. J Power Sources, 81-82:383-7, 1999.

[12] SHENG, L., QI L., YUXI, C., FENGJU, Z., Carbon-coated copperetin alloy anode material for lithium ion batteries. J Alloys Compd, 478:694-8, 2009.

[13] YANG, J., TAKEDA, Y., IMANISHI, N., XIE, J.Y., YAMAMOTO, O., Intermetallic SnSb compounds for lithium insertion hosts. Solid State Ionics, 133:189-94, 2000.

[14] CYRIL, M., MOULAY, T.S., DARWICHE, A., JULIEN, F., BERNARD, F., JEAN, C.J., Study of the series Ti1_y NbySnSb with 0 _ y_1 as anode material for Li-ion batteries. J Power Sources, 244:736-41, 2013.

[15] BO-OK, J., SEOK-HWAN, P., WAN-JIN, L., Electrospun Co-Sn alloy/carbon nanofibers composite anode for lithium ion batteries. J Alloys Compd, 574:325-30, 2013.

[16] JUNGWON, P., JIYONG, E., HYUK, S.K., Fabrication of $\mathrm{Sn}-\mathrm{C}$ composite electrodes by electrodeposition and their cycle performance for Li-ion batteries. Electrochemistry Communications., 11:596-598, 2009.

[17] GÜL, H., AKBULUT, H., ASLAN, S., ALP, A. Effect of reciprocating sliding speed on the tribological performance of nano SiCp reinforced Ni-metal matrix composites produced by electrocodeposition, Journal of Nanoscience and Nanotechnology, 12; 9076-9087 2012.

[18] STROUMBOULI, M., GYFTOU, P., P AVLATOU, E. A., PYRELLIS, N. S., Codeposition of ultrafine WC particles in $\mathrm{Ni}$ matrix composite electrocoatings. Surface \& Coatings Technology, 195 : 325-332, 2005.

[19] DONG, Y.S., LIN P.H., WANG, H.X., Electroplating preparation of $\mathrm{Ni}-\mathrm{Al} 2 \mathrm{O} 3$ graded composite coatings using a rotating cathode. Surface \& Coatings Technology, 200:3633-3636, 2006.

[20] UYSAL, M., CETINKAYA, T., KARTAL, M., ALP, A., AKBULUT, H., Production of $\mathrm{Sn}-$ $\mathrm{Cu} / \mathrm{MWCNT}$ composite electrodes for $\mathrm{Li}$-ion batteries by using electroless tin coating. Thin Solid Films 572:216-223, 2014.

[21] SUNG-KYU, K., SUNG, T., Electrodeposition behavior and characteristics of 
Ni-carbon nanotube composite coatings. Transactions of Nonferrous Metals Society of China, 21:68-72, 2011.

[22] ASHUTOSH S., SUMIT B., RANJAN S., REDDY BSB., FECHT HJ, KARABI, D., Siddhartha D. Influence of current density on microstructure of pulse electrodeposited tin coatings. Materials Characterization, 68:2-32, 2012.

[23] SHI L., SUNA CF., GAO P., ZHOU F., LIU WM., Electrodeposition and characterization of $\mathrm{Ni}-\mathrm{Co}-$ carbon nanotubes composite coatings. Surface \& Coatings Technology, 200, 4870-4875, 2006.

[24] CHEN X.H., CHEN C.S., XIAO H.N., CHENG F.Q., ZHANG G., YI G.J., Corrosion behavior of carbon nanotubes-Ni composite coating. Surface \& Coatings Technology., 191:351-356, 2005.

[25] CHEN X.H., CHENG F.Q., LI S.L., ZHOU L.P., LI D.Y., Electrodeposited nickel composites containing carbon nanotubes. Surface and Coatings Technology, 155, 274-278, 2002.

[26] YUN-XIAO W., LING H., YU-QING C., FU-SHENG K., JUN-TAO L., SHI-GANG S.,
Fabrication and electrochemical properties of the $\mathrm{Sn}-\mathrm{Ni}-\mathrm{P}$ alloy rods array electrode for lithiumion batteries. Electrochemical Community, 12:1226-1229, 2010.

[27] UYSAL M., GUL H., ALP A., AKBULUT H., Sn-Ni/MWCNT nanocomposite negative electrodes for Li-ion batteries: The effect of $\mathrm{Sn}: \mathrm{Ni}$ molar ratio. International Journal of Hydrogen Energy, 39:21391-21398, 2014.

[28] UYSAL M., ÇETINKAYA T., KARSLIOĞLU R., ALP A., AKBULUT H., Production of Sn/MWCNT Nanocomposite Anodes by Pulse Electrodeposition for Li-ion Batteries. Applied Surface Science, 290:6-12, 2014.

[29] HUI, W., ZHEWEI, C., MENGQI, Y., JIANMING, W., JIANQING, Z., Highly ordered nanoporous $\mathrm{Sn}-\mathrm{Ni}$ alloy film anode with excellent lithium storage performance. Materials Letters, 138:139-142, 2015.

[30] JEONG-HOON, J., WON-SIK, K., SEONGHYEON, H., Electrochemical deposition of nanodendritic $\mathrm{Sn} / \mathrm{Cu} 6 \mathrm{Sn} 5$ foam. Materials Letter., 138:33-36, 2015. 